\title{
ЖИЛИЩНОЕ СТРОИТЕЛЬСТВО НА ТЕРРИТОРИИ МОСКОВСКОЙ ОБЛАСТИ И ВСЕХ РЕГИОНОВ РФ, А ТАКЖЕ ЕГО ЭКОНОМИЧЕСКАЯ ОЦЕНКА
}

(c) 2020 Реймер Александра Павловна

студент

Сибирский федеральный университет, Россия, Красноярск

(C) 2020 Мухин Дмитрий Сергеевич

студент

Сибирский федеральный университет, Россия, Красноярск

(c) 2020 Аленичева Анастасия Валерьевна

студент

Сибирский федеральный университет, Россия, Красноярск

(C) 2020 Фалилеева Дарья Александровна

студент

Сибирский федеральный университет, Россия, Красноярск

(c) 2020 Шевченко Михаил Олегович

студент

Сибирский федеральный университет, Россия, Красноярск

В статье рассматривается и исследуется рынок жилой недвижимости по территориальной принадлежности, также в данной статье проводится оценка динамики ввода в эксплуатацию жилой недвижимости на территории Московской области и регионов. Ключевыми вопросами, требующими решения в краткосрочной и среднесрочной перспективе, остаются: поиск путей увеличения платежеспособного спроса; увеличение доступности квартир для большинства целевых групп населения; стимулирование в приобретения жилой недвижимости финансового класса населения; совершенствование всех сфер строительства. Обозначены главные задачи государственной политической жилищной деятельности.

Ключевые слова: Жилищное строительство, реальные доходы, инвестиционная привлекательность, ставка ипотечного кредитования, программно-целевой метод.

Определяющая роль отрасли строительства заключается в разработке условий для динамичного становления экономики государства в целом. Дабы удовлетворить спрос, застройщики осуществляют активный ввод жилья в эксплуатацию. В статистике на территории Российской Федерации за 2019 год было введено в использование около одного миллиона квартир площадь, которых превысила 75 млн. квадратов. В настоящее время строительство представляет собой самостоятельную ветвь экономики государства, целью работы которой является ввод в действие свежих, а также переустройство, обновление, починка и техническое перевооружение действующих объектов капитального строительства. [1].

На сегодняшний день строительство представляет собой самостоятельную ветвь экономики государства, целью деятельности которой является ввод в действие новых, а также реконструкция старых, ремонт и техническое перевооружение действующих объектов капитального строительства.

Структура вводимой в эксплуатацию жилой недвижимости по всем субъектам Российской Федерации выглядит следующим образом: чаще всего самые высокие объемы жилищного строительства приходятся на экономически развитые регионы, и это не с проста, ведь это города миллионники, города с более развитой инфраструктурой, културные центры, города, которые чаще всего посещают туристы. А от иммиграции и постоянно растущего населения и зависит спрос на жилищное строительство, а в будущем и дальнейшее выполнение этого спроса [2].

Стоить отметить, что на территории Республики Башкортостан за 2019 года было введено 


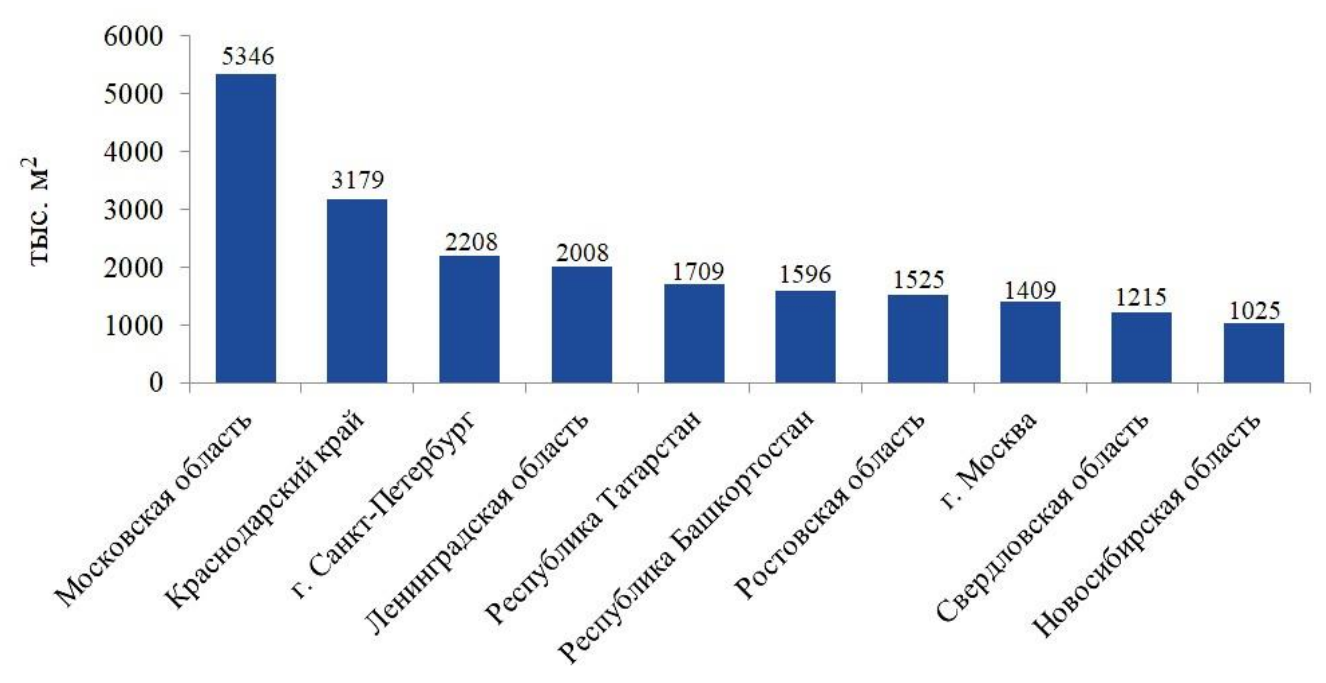

Рисунок 1. ТОП 10 регионов РФ по объему ввода жилья за 2019 год

около 1600 тыс. квадратов жилья. Это на 13\% или примерно на 230 тыс. м $^{2}$ меньше, чем за аналогичный период 2018 года.

Согласно статистическим данным Единого реестра застройщиков пик объемов введенного жилья на территории республики приходится на июнь каждого отчетного года: в июне 2019 года было введено около 300 тыс. м $^{2}$ жилья, что на 12\% меньше, чем за июнь 2018 года и на 16\% ниже, чем за июнь 2017 года [3].

Посмотрев и проанализировав основной индикатор оценки, можно сделать вывод, что строительная отрасль находится в состоянии рецессии, то есть наблюдается умеренный спад и постепенное замедление темпов подъема развития отрасли. По утвержденной Правительством Республики Башкортостан государственной программе «Развитие строительного комплекса и архитектуры Республики Башкортостан» пла- нируемый объем жилья, вводимый в эксплуатацию в 2019 году, составлял 2,67 млн. м2 [4]. Таким образом, на сентябрь 2019 года госпрограмма была выполнена всего лишь на 59,78\%.

Рынок жилой недвижимости инерционен, и последствия кризиса 2014-2015 года стали ощутимыми спустя 1-2 года. Вместе с тем, общая неблагоприятная социально-экономическая ситуация повлияла на сокращение покупательского спроса. А если нет покупателей, то и не будет продавцов, от сюда уже идет спад предложения на рынке жилой недвижимости вследствие падения реальных доходов населения, снижения доступности жилищного ипотечного кредитования, а также роста себестоимости объектов строительства, включающего в себя все издержки в процессе возведения здания. Динамика денежных доходов населения Московской области приведена в таблице 1 [5].

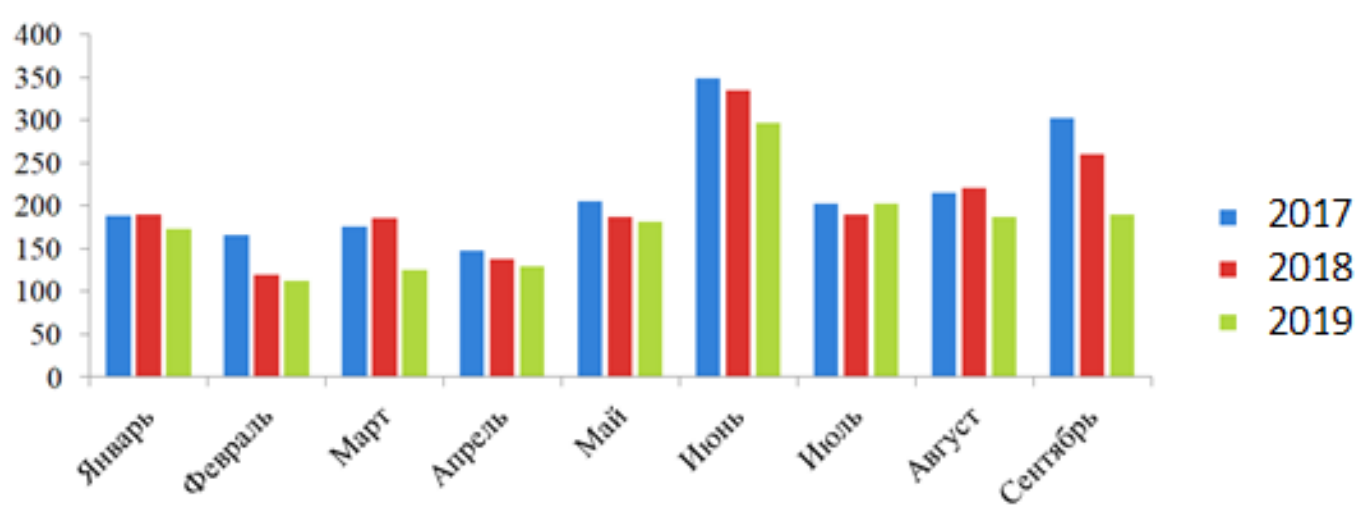

Рисунок 2. Динамика ввода в действие жилья в Московской области по месяцам, тыс. м2 
Таблиц̧а 1. Денежные доходы населения Московской области

\begin{tabular}{|c|c|c|}
\hline & $\begin{array}{c}\text { Среднедушевые доходы, } \\
\text { рублей в месяц }\end{array}$ & $\begin{array}{c}\text { Реальные располагаемые доходы, } \\
\text { в \% к соответствующему периоду } \\
\text { предыдущего года }\end{array}$ \\
\hline \multicolumn{3}{|c|}{2018 год } \\
\hline I квартал & 24118,6 & 107,9 \\
\hline II квартал & 23664,7 & 87,9 \\
\hline III квартал & 31022,9 & 96,1 \\
\hline 9 месяцев & 26268,7 & 96,7 \\
\hline \multicolumn{3}{|c|}{2019 год } \\
\hline I квартал & 24422,0 & 96,1 \\
\hline II квартал & 24964,5 & 102,2 \\
\hline III квартал & 29750,4 & 94,6 \\
\hline 9 месяцев & 26379,0 & 97,3 \\
\hline
\end{tabular}

По итогам января-сентября 2019 года реальные располагаемые доходы населения с учетом оценки инфляции упали на $2,7 \%$ к соответствующему периоду предыдущего года, а за 2018 год на 3,3\% к соответствующему периоду 2017 года.

Нужно обозначить, что купить недвижимость с внедрением рыночных устройств в настоящее время способен узкий круг семей с уровнем доходов выше среднего. Ведущего основания низкого платежеспособного спроса на жилье являются невысокая заработная плата населения, об этом цифры говорят сами за себя, уровень средней зарплаты по стране ничтожно мал. Россия занимает лишь 67 место среди других стран, и разрыв от первого места достаточно велик [6].

Также влияние оказывает и слабая доступ- ность долгосрочных ипотечных жилищных кредитов и завышенная ставка ипотечного кредитования. Динамика уровня ставки ипотечного кредитования приведена на рисунке 4.

Уровень средневзвешенной ставки по ипотечному жилищному кредитованию в январе-сентябре 2016 года колебался около $12-12,3 \%$, но после повышения ключевой ставки Центрального Банка Российской Федерации поднялся за январь-сентябрь 2017 года до 14,7\%. Однако за отчетный период 18-2019 года наблюдается умеренный спад уровня ставки до $11 \%$. Это происходит из-за скачков инфляции, проще сказать, что в ипотечных ставках заложены ожидания по будущей инфляции, и от того какой она будет зависит процент будущей ставки.

Одновременно в 2016 году резко выросли

\begin{tabular}{|l|l|l|}
\hline Позиция & Название государства & Средняя 3П в \$ \\
\hline 1 & Швейцария & 5426,27 \\
\hline 2 & Пюксембург & 3565 \\
\hline 3 & Катар & 3372,63 \\
\hline 4 & Австрапия & 3306,13 \\
\hline 5 & Обьериненные Арабские Эмираты & 3182,48 \\
\hline 66 & Литва & 668,39 \\
\hline 67 & Россия & 637,7 \\
\hline 68 & Иордания & 619,35 \\
\hline 69 & Уругвай & 613,12 \\
\hline 70 & Намибия & 601,08 \\
\hline
\end{tabular}

Рисунок 3. Средняя зарплата по странам мира за 2019 


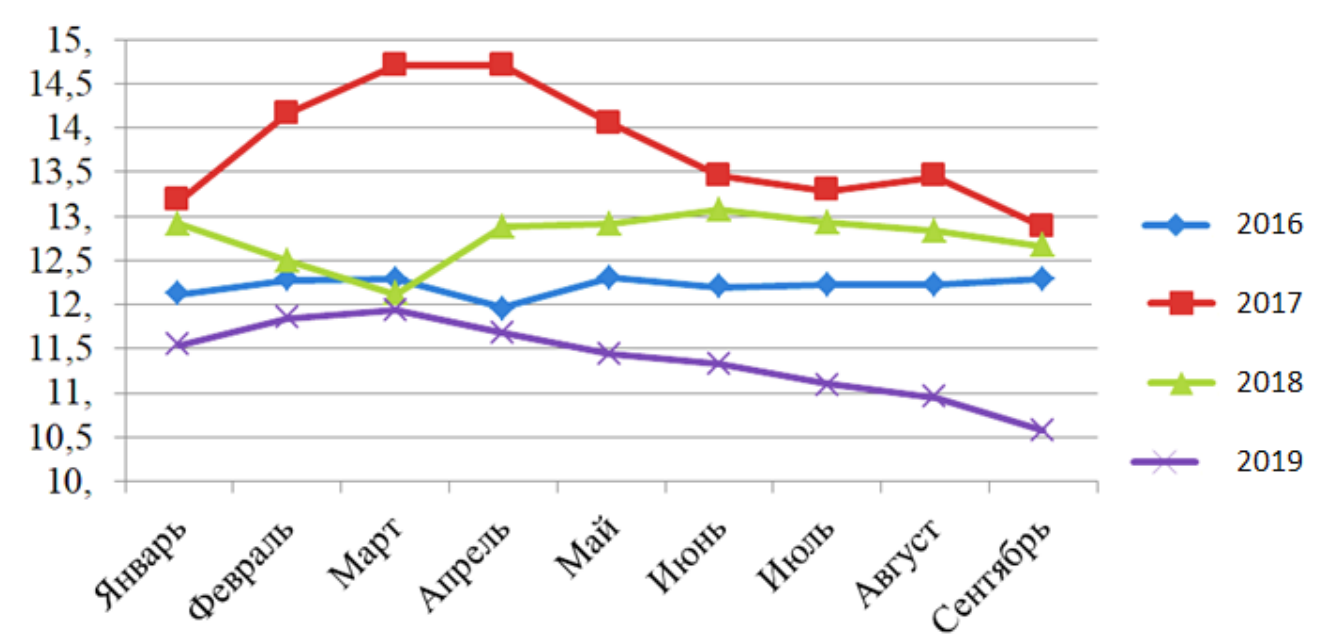

Рисунок 4. Динамика уровня ставки по ипотечному кредитованию,\%

банковские ставки по кредитованию застройщиков, которое в условиях отсутствия возможности получения денег, как в Центральном Банке России, так и в западных банках практически прекратилось.

На углубляющийся негативный тренд в текущей экономической ситуации в будущем может повлиять и накаляющаяся ситуация в мире, а именно рост курса доллара, вызванный обвалом нефти и пандемией коронавируса. Сама болезнь негативно скажется не только на России, но и на всем мире в целом. Закроются границы, остановится работа, упадет спрос на все, большинство мелких предпринимателей обанкротится, а это приведет к тому, что многие люди потеряют свое место работы, за короткий срок. Люди начнут экономить на всем, что уже говорить о недвижимости.

Что же касается Республики, то здесь все указывает на инвестиции в основной капитал Республики Башкортостан. Так в 2017 году значение индекса инвестиций находилось в отри- цательной зоне (-2,9\%). При этом в 2018 году темпы роста инвестиций вновь увеличились и достигли уровня 102,5\% относительно 2017 года. А в 2019 году наблюдается спад индекса на 32,5\% [2]. Динамика индекса инвестиций приведена на рисунке 5.

Вследствие сокращения покупательского спроса на жилую недвижимость и ужесточения требований в сегменте банковского кредитования для строительных организаций актуальной стала проблема нехватки оборотных средств. Из-за этого многие строительные организации не смогли принять участие в аукционах по приобретению земельных участков. К тому же застройщики оказались в такой ситуации, в необходимости «заморозить» значительное количество инвестиционно-строительных проектов, оказавшихся на стадии получения исходно-разрешительной документации, а еще задерживать темпы начатого строительства, вплоть до его абсолютной остановки. Все это привело к отрицательной тенденции развития

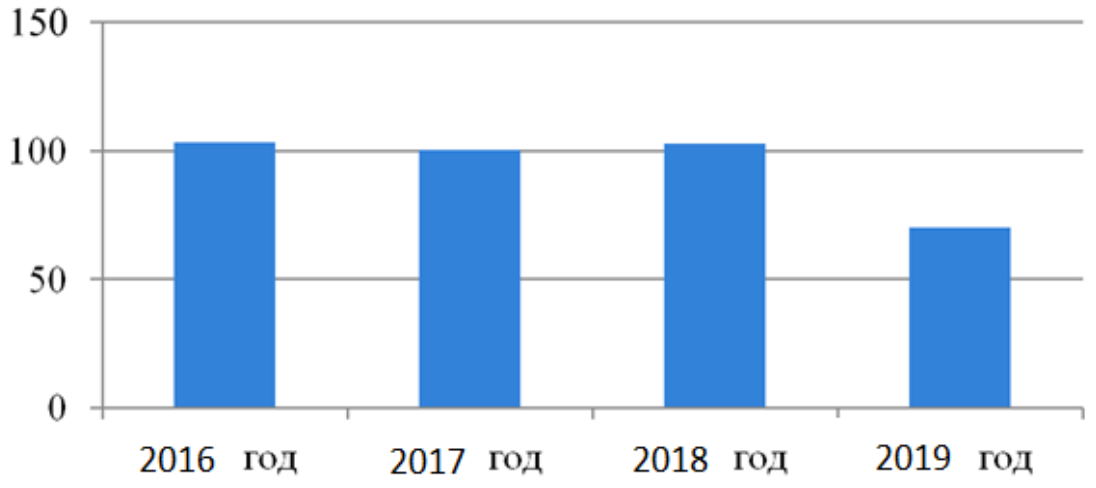

Рисунок 5. Динамика индекса инвестиций, \% 
жилищного строительства на территории Республики Башкортостан и иных государств.

По оценкам экспертов, для планомерного обновления жилищного фонда и удовлетворения потребностей населения необходимо практически полное обновление большей части российского жилищного фонда, а для начала нужно определить стратегию и конечные результаты необходимого обновления. В каждом жилье необходимо обеспечить ввод не менее 1 м2 нового жилья на душу населения ежегодно (так по официальным данным Росстата в 2019 году в среднем по Башкирии эта цифра составила 0,61 м2), хотя по официальным источникам ежегодный прирост жилищного фонда в республике должен составлять около 4,06 млн. м2, но на деле мы наблюдаем совсем другую картину, реальный показатель далек от того, который нам необходим, разница отличается в 1,6 раз.

Таким образом, задача создания условий для совершенствования горажанами республики жилищных условий настоятельно рекомендует от региональных властей улучшения законодательной и нормативной базы в жилищном секторе. Надобность незамедлительного перехода к более устойчивому функционированию и развитию жилищной сферы определяет необходимость применения программно-целевого способа.

С 2015 года ключевым инструментом реализации государственной политики в сфере жилищного строительства выступает официальная государственная программа «Становление строительного комплекса и архитектуры Республики Башкортостан». Фондом жилищного строительства разработана республиканская подпрограмма «Стимулирование развития жилищного строительства в Республике Башкортостан на 2015-2020 гг.». Ведущей целью считается создание условий для обеспечения планомерного и устойчивого роста объемов ввода жилой недвижимости. Для достижения указанной цели необходимо решение следующих задач [3]:

- обеспечить инженерной инфраструктурой пустые территории для строительства на них объектов жилой недвижимости;

- обеспечить территории Республики Башкортостан документацией по планировке территорий и республиканскими нормативами градостроительного проектирования;

- обеспечить скорейшее переселения граждан и произвести замену аварийного и ветхого жилья в новые объекты строительства, ветхое жилье под снос;

- обеспечить многодетные семьи и семьи с доходом ниже среднего (малообеспеченных) социальным жильем;

- оказать частичную поддержку от государства, семьям, которые имеют обязательства, в виде субсидий и сертификатов;

- создать все необходимые условия для работающих граждан, спешивших приобрести жилье, за счет собственных и заемных средств.

Итогами программы должны стать:

- значительный рост объемов жилой недвижимости, вводимой в эксплуатацию;

- рост объемов работ по виду деятельности «Строительство»;

- увеличение коэффициента доступности жилья;

- увеличение доли расселенного аварийного жилья в общей площади аварийного и ветхого жилья;

- увеличение инфраструктуры.

Срок реализации подпрограммы - 20152020 годы без деления на этапы.

Но не будем забывать о том, что, когда ставились задачи на эти сроки, никто и не предполагал, что могут появиться причины, не зависящие не от каких факторов, а именно пандемия коронавируса. И теперь, чтобы перейти к решению уже поставленных задач, нам нужно объединиться и придумать противоядие против нашего «общего врага».

Также следует отметить необходимость низких ставок по кредитам. Несмотря на их снижение в последнее время они продолжают находиться на достаточно высоком уровне, что сдерживает инвестиции компаний, которые могли бы быть сделаны за счет заемных средств. Немаловажную роль играет повышение эффективности взаимодействия застройщиков и региональных органов власти, направленное на расширение возможностей партнеров и ускорение процедур выдачи гарантий, а также на повышение доверия населения к ипотечному кредитованию.

Обо всем вышесказанном можно сказать, что в настоящее время в сфере строительства существуют проблемы. Рассмотренные выше задачи необходимые для решения проблем, направлены на повышения качества предоставляемых населению. В общей степени это позволит установить устойчивый рост в экономике и удовлет- 
воренность граждан жилищными условиями.

Таким образом, на сегодняшний день в области строительства существует ряд проблем. Рассмотренный выше комплекс мероприятий направлен на повышение качества предоставляемых населению. В целом это позволит обеспечить устойчивый экономический рост и удовлетворенность граждан жилищными условиями.

\section{Библиографический список}

1. О жилищном строительстве в 2019 году [электронный ресурс] - Режим доступа - URL: https://www.gks.ru/ bgd/free/b04_03/IssWWW.exe/Stg/d05/20.htm (Дата обращения 24.03.2020)

2. Рейтинг регионов России по вводу жилья в 2019 году [электронный ресурс] - Режим доступа - URL: https:// ria.ru/20190520/1553368646.html (Дата обращения 24.03.2020)

3. Динамика ввода жилья в федеральных округах Российской Федерации за 9 месяцев 2019 года [электронный ресурс] - Режим доступа - URL: https://strategy24.ru/rf/news/dinamika-vvoda-zhilya-v-rossiiuvelichivaetsya-4 (Дата обращения 24.03.2020)

4. Об утверждении государственной программы «Развитие строительного комплекса и архитектуры Республики Башкортостан» [электронный ресурс] - Режим доступа - URL: http://docs.cntd.ru/document/430565714 (Дата обращения 24.03.2020)

5. Денежные доходы населения Московской области [электронный ресурс] - Режим доступа - URL: https:// knoema.ru/atlas/Российская-Федерация/Московская-область/topics/Доходы-и-расходы-населения (Дата обращения 24.03.2020)

6. Средние зарплата мира за 2019 год [электронный ресурс] - Режим доступа - URL: https://zen.yandex.ru/ media/achtoskazheshti/na-kakom-meste-v-mire-rossiia-nahoditsia-po-urovniu-srednei-zarplaty-skolkopoluchaiut-za-granicei-5d8c30d97cccba00af2198еа (Дата обращения 24.03.2020) 